Vol. LXIV No $1 \quad 2014$

\title{
IMPROVING ELECTRICAL EFFICIENCY OF EDM POWER SUPPLY
}

\author{
EMANOIL TOMA \\ Faculty of Engineering, “Lucian Blaga” University of Sibiu, Romania, emanoil.toma@ulbsibiu.ro \\ CARMEN MIHAELA SIMION \\ Faculty of Engineering, “Lucian Blaga”University of Sibiu, Romania, carmen.simion@ulbsibiu.ro
}

\begin{abstract}
This paper briefly presents the principal types of Pulse Generators for Electrical Discharge Machining and ways to improve electrical efficiency. A resonant converter with series-parallel LCC circuit, for EDM applications, was analyzed by PSpice simulation. The performances of EDM Power Supply were improved by adding an energy recovering - voltage limiter circuit. The shape of current pulse was changed by adding a supplementary MOSFET Switch in parallel with the gap. Two or more converters can be parallelized, in this way output current can be changed. A bloc-schema was conceived for EDM experimental set up.
\end{abstract}

Keywords: Pulse Generator, Current Limiting, Resonant Converters, Current Source

\section{Introduction}

In Electrical Discharge Machining an electric high voltage is applied between Electrode Tool (ET) and Work Piece (WP). Usually a dielectric liquid is present in the gap which has the dimension between $5 \mu \mathrm{m}$ and $20 \mu \mathrm{m}$. After a delay time, (unknown, dependant of dielectric state, surface state etc.), an electric spark start up between ET and WP. Voltage decrease at a low level (20-30V) and current increase to a level limited by the electrical power supply.

Figure 1: Die Sinker Electrical Discharge Machining Principle

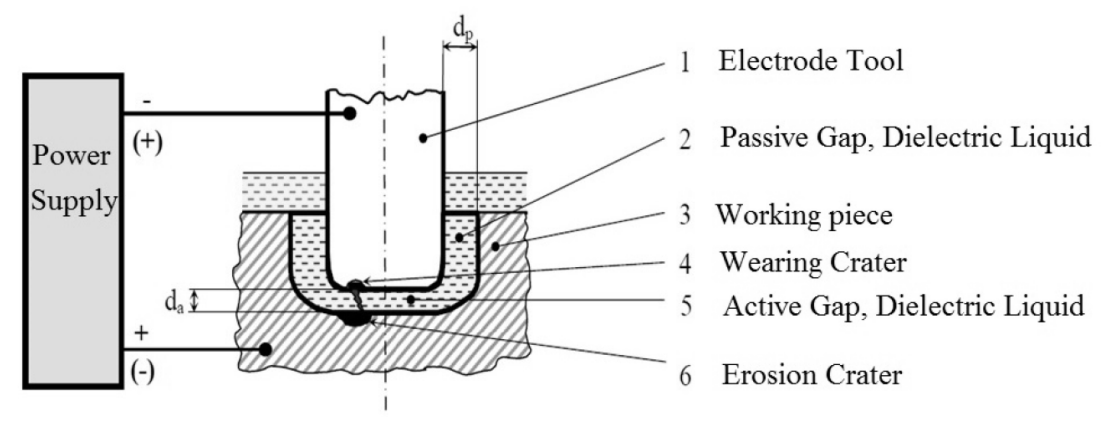

A complex of phenomenon determines an erosion crater on the work piece and a wearing crater in the electrode tool. The debris appears in the gap and its must be eliminated. For this is necessary to stop the current through the gap for a time period.

\section{Pulse Generators}

The Pulse Generator applies the electrical voltage between Electrode Tool and Working Piece, necessary for Electrical Discharge Machining (EDM). On the earlier EDM machines RC pulse generator was used.

Figure 2: RC Pulse generator for EDM 


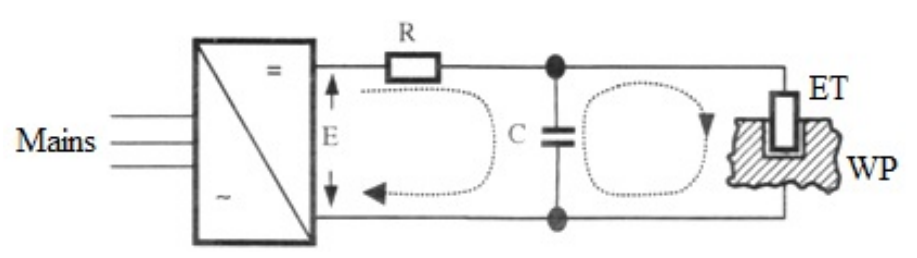

The control of pulse parameters is difficult and efficiency is poor $(20 . .40 \%)$. But the frequency of pulses can be high (above 1MHz) and this type of generator is actually used in micromachining.

Controlled Pulse generator with resistive limiting current use an electronic switch and a resistor. The variant which have switch in parallel is not used for his very poor energetic efficiency.

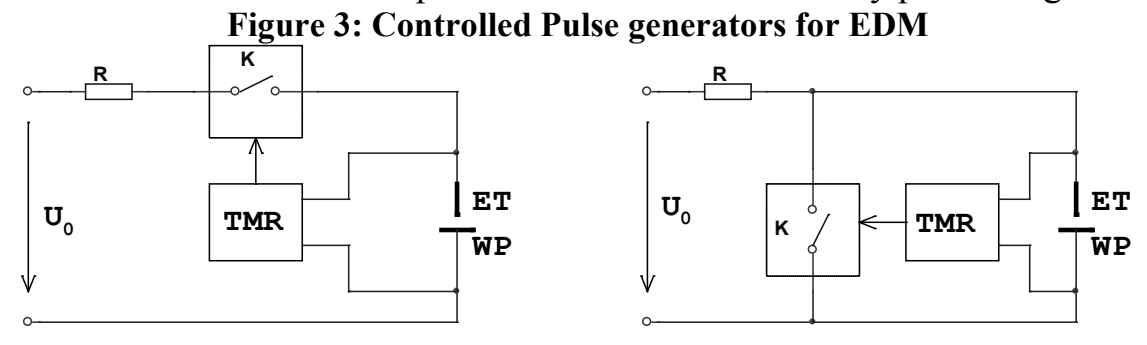

The timers electronic bloc (TMR) imposes pulse duration. The typical diagram for normal discharge (roughing Die Sinker EDM Technology) is shown in figure 4, where:

Figure 4:The typical diagram of voltage and current pulses for normal discharge

- $\mathrm{U}_{\mathrm{o}}$ is the breakdown voltage and its value is fixed by power supply. $U_{0}$ has a value between $100 \mathrm{~V}$ and $300 \mathrm{~V}$.

- $\mathrm{U}_{\mathrm{d}}$ is the discharge voltage, and it has a little fall and radiofrequency noise. $\mathrm{U}_{\mathrm{d}}$ has a value between $20 \mathrm{~V}$ and $30 \mathrm{~V}$. The radiofrequency noise has the maximum power spectrum in $50 \mathrm{MHz}-90 \mathrm{MHz}$ range.

- $I_{d}$ is the current value during the discharge (1A....10A.......200A)

- $t_{r}$ is the rise time of voltage pulse.

- $t_{\mathrm{m}}$ is the holding time of the ignition voltage.

- $t_{\mathrm{s}}$ is the starting discharge time.

- $t_{a}$ is the ignition delay time.

- $t_{d}$ is the discharge time.

- $t_{u}$ is the voltage pulse width $(1 \ldots 3000 \mu \mathrm{s})$

- $t_{p}$ is the pause time $(1 \ldots 3000 \mu \mathrm{s})$.

- $\mathrm{T}$ is the period of the voltage pulses.

- $\mathrm{t}_{\mathrm{i}}$ is the current pulse width.

The energy for one discharge is :

$$
w_{i}=\int_{0}^{t_{u}} u(t) \cdot i(t) \cdot d t
$$

The amplitude of current pulse is:

$$
i_{d}=\frac{U_{0}-u_{d}}{R} \cong \text { const }
$$

Results:

$$
w_{i}=u_{d} \cdot \frac{U_{0}-u_{d}}{R} \cdot t
$$

where:

$$
t_{i} \cong t_{u}-t_{a}
$$


Delay ignition time $t_{a}$ is a stochastic variable, depending on the gap state. TMR command bloc defines the control mode by imposing parameters $t_{u}$ and $t_{i}$, which, in conjunction with amplitude of current pulse determine the energy pulse. [65]. The principal working modes are: izopuls mode, where $t_{i}$ and implicit $\mathrm{w}_{\mathrm{i}}$ are constant, and izofrequency mode, where $t_{\mathrm{u}}$ is constant. In the izopuls mode the control of process is more accurate and the technological results are better.

Analyzing the principia schema (figure 3a) and the chronograms (figure 4), results that difference between ignition voltage $U_{0}$ and gap voltage $U_{d}$ is supported by $R$ during the discharge time period $\left(t_{i}\right)$.

Considering ideal switch $(\mathrm{K})$, dissipated power on the resistor is:

The consumed power is:

$$
\begin{aligned}
& p_{d}=\left(U_{0}-u_{d}\right) \cdot i_{d} \\
& P_{c}=U_{0} \cdot i_{d} \\
& p_{u}=u_{d} \cdot i_{d}
\end{aligned}
$$

The utile power is:

Results the efficiency of Pulse Generator : $\eta=\frac{P_{u}}{P_{c}}=\frac{u_{d}}{U_{0}}$

For a small difference between ignition voltage $U_{0}$ and gap voltage $U_{d}$ the efficiency can be acceptable (eq. $\mathrm{U}_{\mathrm{d}}=24 \mathrm{~V} ; \mathrm{U}_{0}=60 \mathrm{~V}$, the efficiency is $40 \%$ ). But for high ignition voltage the efficiency is very poor (eq. $\mathrm{U}_{\mathrm{d}}=24 \mathrm{~V} ; \mathrm{U}_{0}=300 \mathrm{~V}$, the efficiency is $8 \%$ ). Using two power supplies, one having high voltage - low current for ignition, and another having low voltage - high current for sustaining the discharge process, efficiency can be acceptable.

Figure 5: Two sources pulse generators for EDM
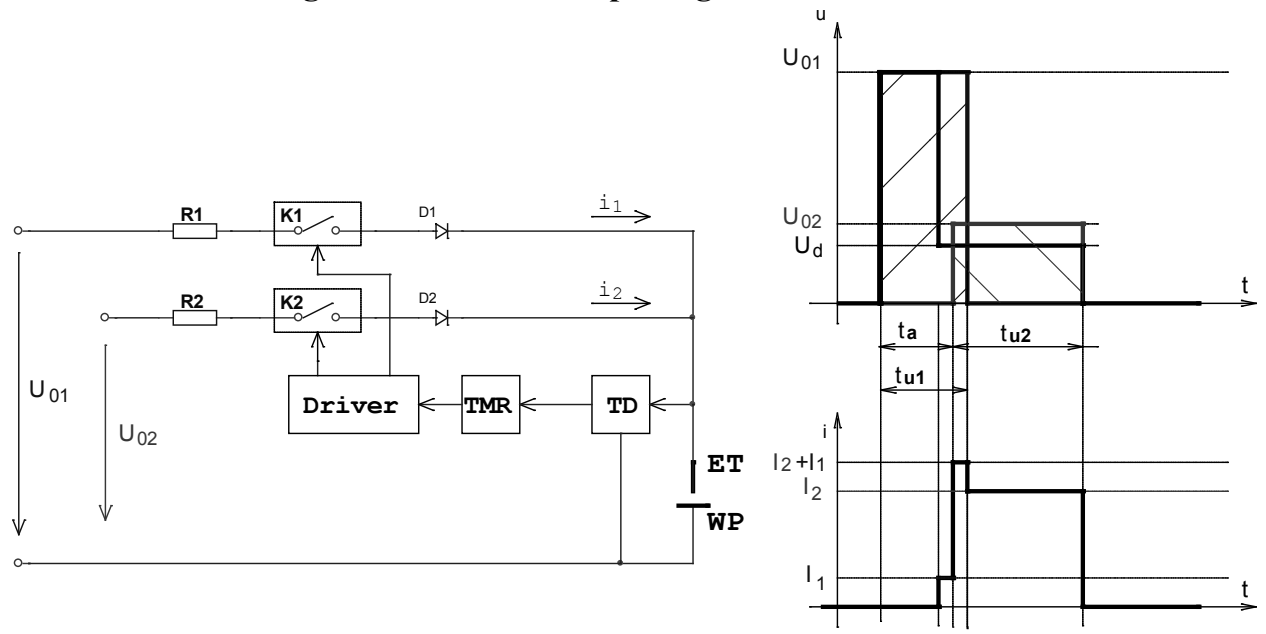

Driver bloc assures properly command for switches, TMR bloc imposes time duration for pulses, Threshold Detector (TD) senses the moment of discharge apparition for starting the timers. The efficiency can grow around $50 \%$ (eq. for: $\mathrm{U}_{\mathrm{d}}=24 \mathrm{~V} ; \mathrm{U}_{01}=300 \mathrm{~V} ; \mathrm{U}_{02}=45 \mathrm{~V}$ ).

For increasing the efficiency is necessary to replace the limiting current resistor $\mathrm{R}$ by a coil with inductance L and adopt the chopper technique for limiting the current. Step Down (Buck) Converter can be used in a closed loop to control the value of current intensity as is shown in figure 6a. Current sensing bloc (CS) provides a voltage proportional with current and this value is compared with reference. The error amplifier commands PWM module and finally the switch $\mathrm{K}$.

Figure 6: Buck Converter as a Current Source

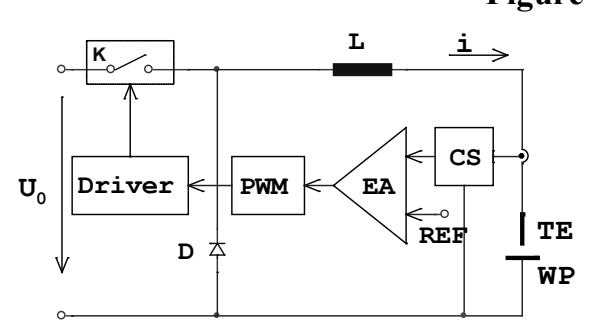

a)

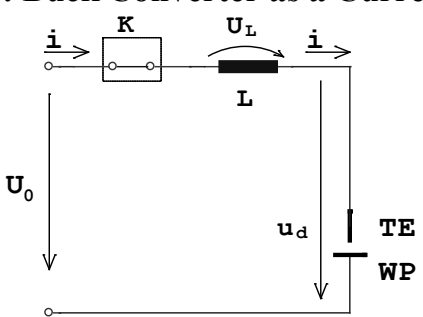

b)

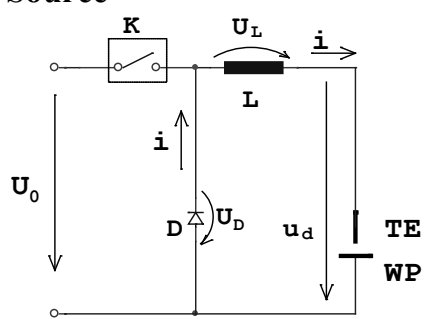

c) 
In figure $6 \mathrm{~b}$ the switch $\mathrm{K}$ is "ON", and, assuming ideal circuit elements, results:

$$
\begin{aligned}
& U_{L}=U_{0}-u_{d} \\
& U_{L}=L \cdot \frac{d i_{L}}{d t} \\
& \frac{d i_{L}}{d t}=\frac{U_{0}-u_{d}}{L} \cong \frac{U_{0}}{L}
\end{aligned}
$$

The current increases with high slope. In figure $6 \mathrm{c}$ the switch $\mathrm{K}$ is "OFF" and results:

$$
\begin{aligned}
& U_{L}=-U_{D}-u_{d} \\
& \frac{d i_{L}}{d t}=\frac{-U_{D}-u_{d}}{L} \cong-\frac{u_{d}}{L}
\end{aligned}
$$

The current decreases slowly. Because after the EDM pulse is finished current decreases too slowly (figure 7), an another switch is necessary. In figure 8 are showed electrical schema and chronograms.

Figure 7: Chronograms for Buck Converter

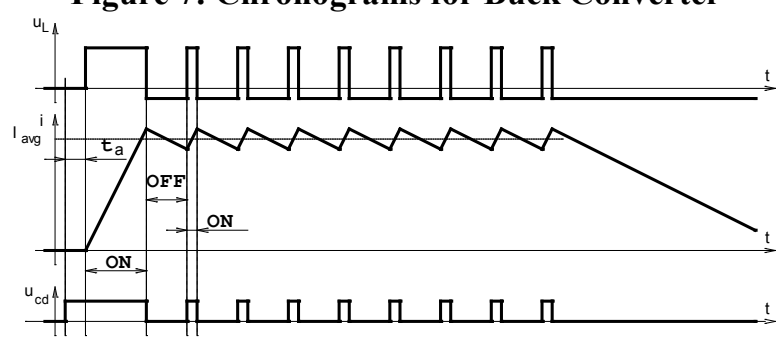

Figure 8: Controlled Pulse Generator with Buck Current Source: Schema and chronograms

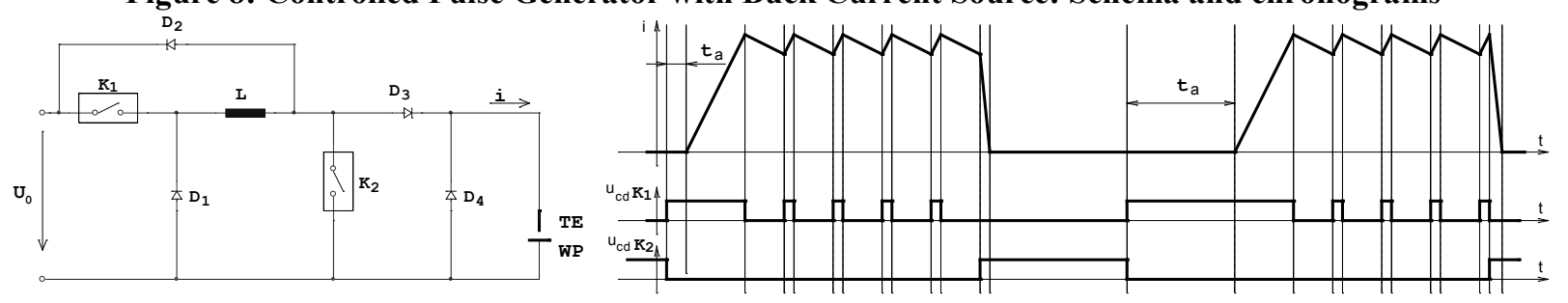

The supplementary diodes prevent undesirable phenomenon: $\mathrm{D}_{2}$ prevents upper voltage, $\mathrm{D}_{3}$ - the inverse current and $\mathrm{D}_{4}$ - the inverse voltage. The authors have simulated the principia schema by emulating the principals states of gap (high resistor in parallel with small capacitor for pre-ignition state and switch in series with small resistor for discharge state). The efficiency increased to $70 . .75 \%$ for high input voltage $\mathrm{U}_{0}=300 \mathrm{~V}$. The most important power losses are during the switching time when an important voltage and current appear on the power electronic devices (especially for $\mathrm{K}_{1}$ and $\mathrm{D}_{1}$ ). The efficiency can be improved by decreasing $\mathrm{U}_{0}$ at $100 \mathrm{~V}$, recovering the energy stored on the core magnetic field and adopting interleaving technique [Lin (2011)].

The efficiency can be improved for a high value by minimizing the switching stress for power electronic devices. The resonant and quasi-resonant converters ensure commutation on low voltage (ZVS-Zero Voltage Switching) or on low current (ZCS-Zero Current Switching), but not for all load conditions. In EDM process the equivalent load resistance for power supply has different values, depending on the gap state (open-circuit in pre-ignition state, low resistance on normal discharge (dependant on the programmed current) and very low resistance on short-circuit conditions).

The resonant circuit which has two capacitors, one in parallel with load (or equivalent resistance load) and one in series, presents an AC current source behavior at $\omega_{0}$ resonant frequency. In figure $9 \mathrm{~b}$ is presented circuit used for Pspice AC simulation, in figure 10 are shown the results of simulation, where you can see the frequency $\mathrm{f}_{0}=148 \mathrm{KHz}$ at which the circuit has current source behavior.

The complete schema for EDM pulse generator simulation is shown in figure 11. The independent sources V1A and V1B assure command sequences for both diagonals of MOSFET bridge. The source V6 permits or inhibits command for bridge transistors and determines EDM pulse durations $t_{u}$ and $t_{p}$. The voltage dependent sources EG1...EG4 command transistors X1...X4 between gate $(G)$ and source (S). The source V5 commands the switch transistor X5 and determines the duration $\mathrm{t}_{\mathrm{i}}$. 
Figure 9: Series-parallel LCC resonant circuit for AC analyze

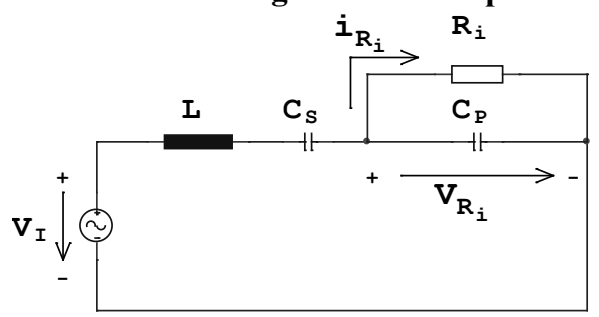

a)

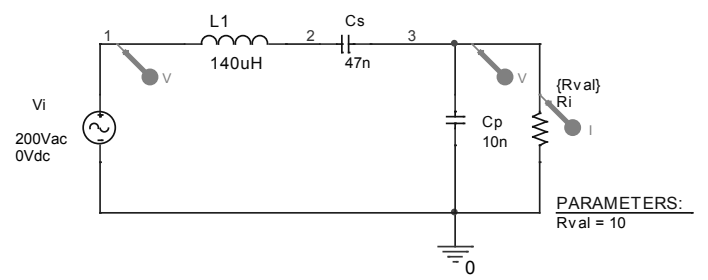

b)

Figure 10: The frequency behavior of series parallel LCC resonant circuit

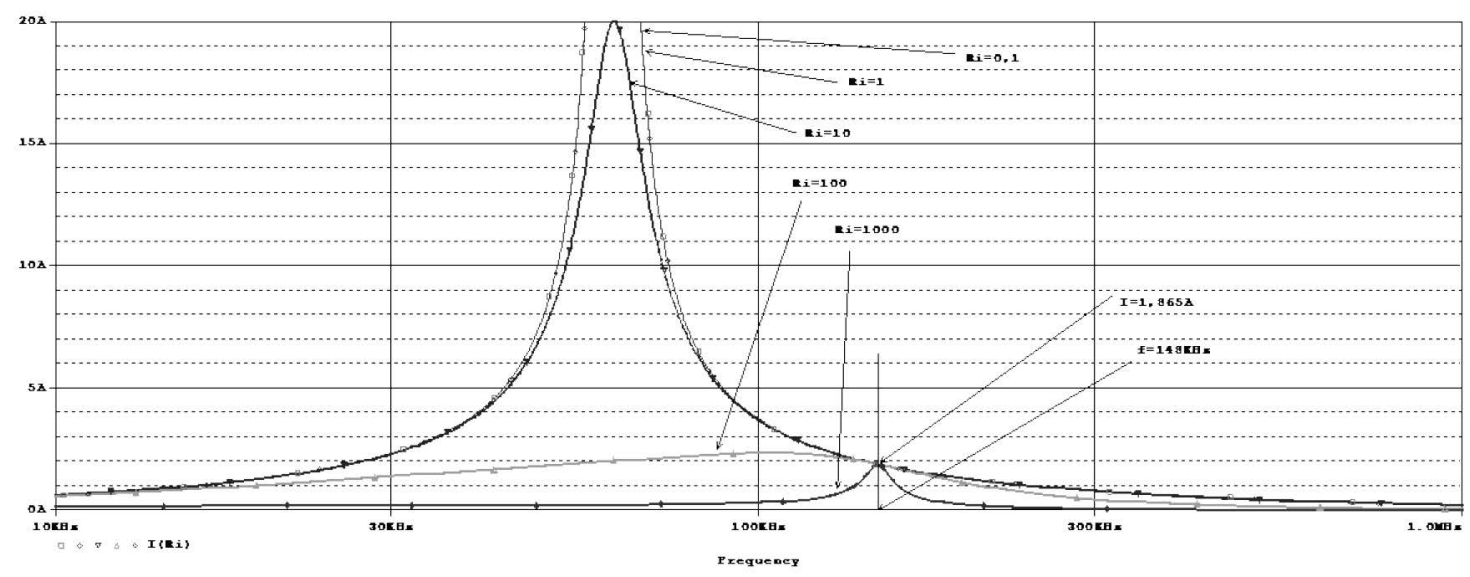

Figure 11: Electrical schema used in PSpice simulation of EDM-LCC Pulse Generator

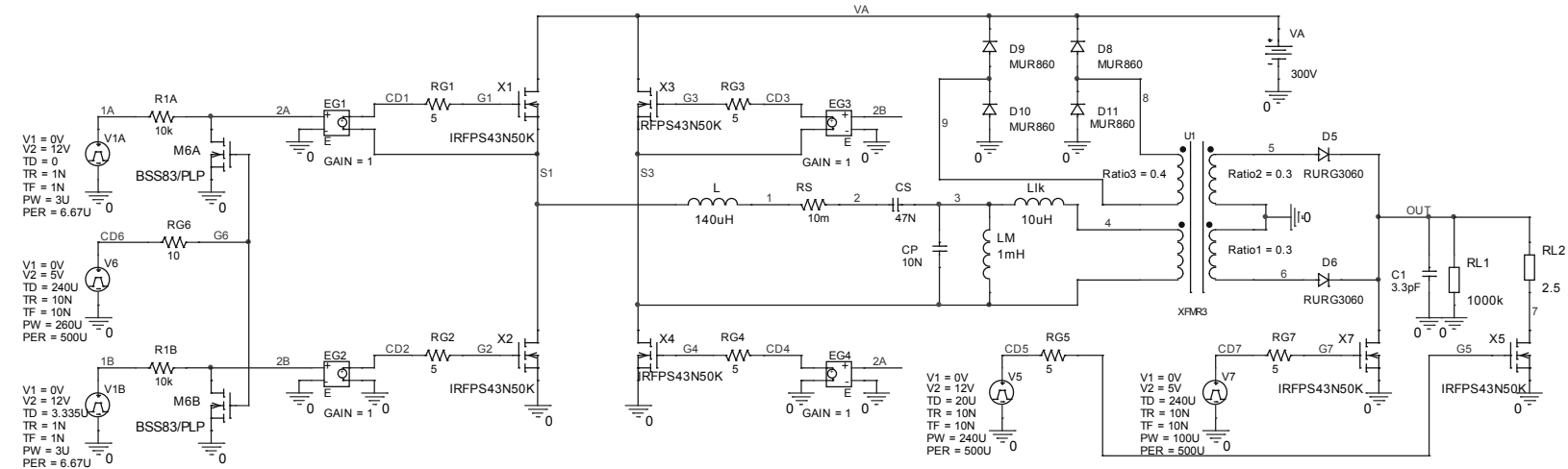

The resonant inverter has as load a high frequency transformer (U1), which has a null point rectifier with diodes D5 and D6 in secondary. Because we use an ideal model for transformer, magnetizing inductance $\mathrm{L}_{\mathrm{M}}$ is added in exterior and also a leakage inductance $\mathrm{L}_{\mathrm{k}}$. For $3 \mathrm{~F} 3$ ferrite core type the working frequency in $100 \mathrm{KHz}$. . $200 \mathrm{KHz}$ is ideal for a good volume-losses performance, we used $150 \mathrm{KHz}$ frequency command for the resonant LCC bridge inverter. In figure 12 are showed the results of the simulation; the ignition voltage is not applied very fast. For eliminating this inconvenient the switch $\mathrm{X} 7$ is $\mathrm{ON}$ during $\mathrm{t}_{\mathrm{p}}$ duration and remains $\mathrm{ON}$ in the first microseconds when we apply command for bridge switches. The current through the L resonant tank increased and the energy stored in the magnetic field will be capable to increase rapidly the voltage applied to the gap when X7 becomes OFF. In figure 13 is showed the results of simulation for two interleaved LCC resonant Converters with $\mathrm{X} 7$ action. Also $\mathrm{X} 7$ in $\mathrm{ON}$ state resolve the problem of slow decreasing gap current when the EDM pulse is in $t_{p}$ time interval. The discharge current has a shape near to ideal "DC" shape when the number of interleaved converters increased. In figure 14 we have conceived a schema for the future experimental set-up. A digital signal controller assures the commands for all the converters and stepper motor drive and has implemented software control strategy. 
Figure 12: The EDM pulse for one stage of LLC converter without the action of X7

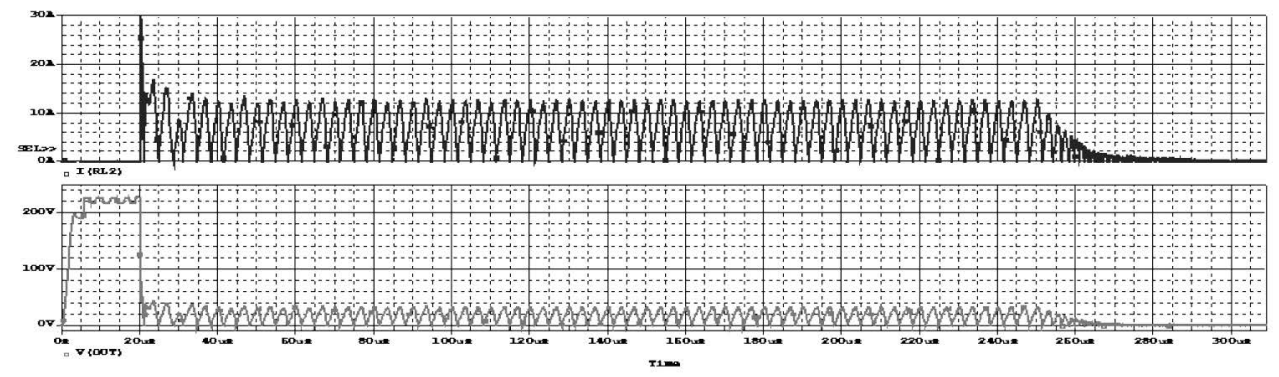

Figure 13: The EDM pulse for two interleaved stage of LLC converter with the action of X7

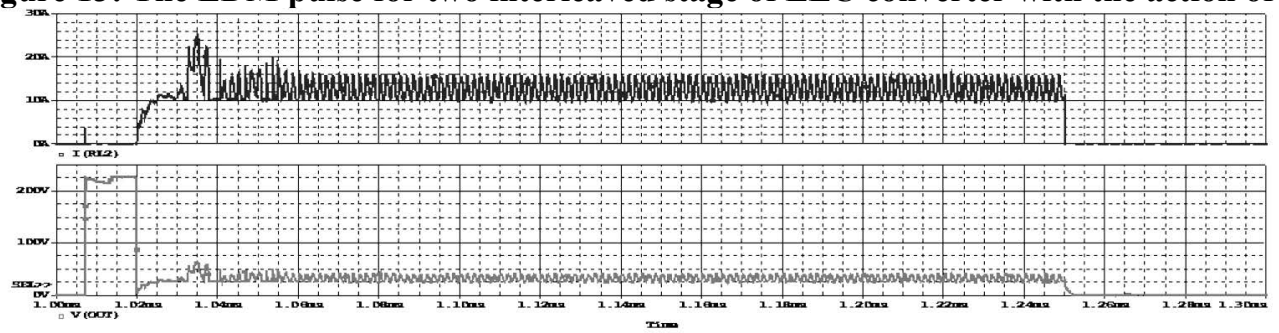

Figure 14: The conceived experimental set-up bloc schema

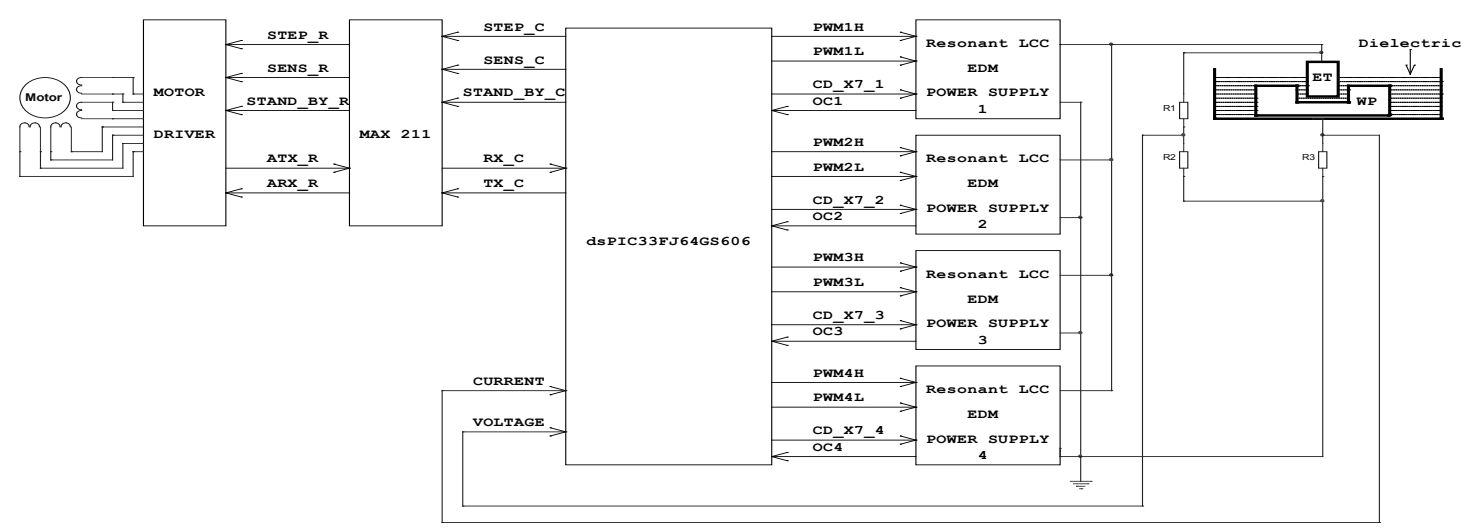

3. Conclusions

The RC pulse generators are actually used in micromachining, where the amplitude of current is several amperes, working at a repetitive frequency above $1 \mathrm{MHz}$, but the efficiency is poor $(20 . .40 \%)$.

The controlled pulse generators with resistive limiting current offers a good control of pulses shape, but efficiency is poor $(20 \ldots 50 \%)$. The inductive limiting current increases efficiency at $70 . .75 \%$. The resonant LCC converter with energy recovering circuit, used for EDM pulse generator increases efficiency at $80 . .85 \%$. Parallelizing two or more LCC interleaved convertors, the current will be stepping increased and the harmonics will be diminish. The supplementary switches can configure the shape of EDM pulses. The control and command are assure by microcontroller (DSC).

\section{References}

- Kunieda, M.; Lauwers, B.; Rajurkar, K.P.; Schumacher B.M. (2005) - Advancing EDM through Fundamental Insight into the Process, CIRP Annals - Manufacturing Technology, Volume 54, Issue 2, p. 64-87.

- Läuter, M.; Casanueva, R.; Schulze H.P.; Azcondo, F. J; Wollenberg, G. (2005) - Development Trends of Process Energy Sources for Special Applications of the Spark Erosion, ICNcT 2005, Bucureşti, in: Nonconventional Technologies Review no.1, ISBN 973-718-357-6, p. 15-26.

- Lin, L.; Hsu C.-C.; Changchien S.-K. (2011) - Interleaved Four-Phase Buck-Based Current Source With Center-Tapped Energy-Recovery Scheme for Electrical Discharge Machining, IEEE Transactions on Power Electronics, Volume: 26, Issue: 1, p. 110 - 118.

- Nanu, D. ş.a. (2004) - Tratat de tehnologii neconvenţionale - Vol.II - Prelucrarea prin eroziune electrică, Editura ULBS, Sibiu, ISBN 973-695-071-9. 